\title{
A Web Application for Simulating Future Settlement Development
}

Gl_Forum 2021, Issue 2

Page: 215 - 227

Full Paper

Corresponding Author:

yingwen.deng@researchstudio.at

DOI: 10.1553/giscience2021_02_s215

\author{
Yingwen Deng', Wolfgang Spitzer', Sabine Gadocha' ${ }^{1}$ and Thomas Prinz',2 \\ 'Research Studios Austria Forschungsgesellschaft mbH - Studio iSPACE, Salzburg \\ 2Salzburg University
}

\begin{abstract}
With the growing residential development of urban areas and their hinterlands in the Alpine region, urban sprawl is a major concern. It is therefore essential for decision-making authorities and urban planners to monitor the demand for, and consumption of, the limited reserve of land zoned for residential buildings and the development of future settlements. Data such as demographic statistics, population forecasts, and geospatial data of the land reserve are required for this purpose. However, due to the variety of these data, tools for exploring them in an integrated and intuitive manner are rarely available.

This paper introduces a web application designed to facilitate this task, a map-based strategical dashboard that was developed within the Alpine Building Centre project (Zentrum Alpines Baven, www.alpinesbaven.at). The paper describes the application's design goals, data preparation, architecture and user interface. With a use case in Oberndorf bei Salzburg, we demonstrate how the application visualizes the predicted future settlement situation based on existing housing patterns and population development forecasts. The use case also shows how the application allows simulation and evaluation of various scenarios for housing demand and zoned residential land use, thus assisting decision makers to devise spatial development concepts for balancing housing sufficiency and reducing urban sprawl. This paper aims to present the application as an approach of using an interactive map-based dashboard to present and utilize multidimensional data in the field of residential land use for the purposes of urban planning.
\end{abstract}

\section{Keywords:}

web map, dashboard, residential land use, spatial planning, settlement development

\section{Introduction}

Demographic change, trends towards smaller household sizes, rising housing demand and costs, and urban sprawl are current challenges for the development of settlements in Salzburg state. To cope with these challenges, as the guidelines for the 'spatial development concept' (Räumliches Entwicklungskonzept) for municipalities in Salzburg state mentions, it is essential to link the development of settlements and population with each other (Land Salzburg, 2019). Therefore, a tool for monitoring the demand for, and consumption of, the limited reserve of 
land zoned for residential building and the development of future settlements is needed. In earlier studies and projects, several tools designed to help with settlement planning were developed. For example, the Flächenmanagement Datenbank is available to municipalities in Bavaria to record and manage internal development potentials (Bayerisches Landesamt für Umwelt, 2018). It can estimate housing demand based on statistical parameters. RAUM + Monitor was developed as an online survey platform to inspect and maintain settlement area reserves, with particular attention being paid to the demand for new building land (RheinlandPfalz, 2015). However, interactive visualization techniques were barely used in these tools.

A map-based dashboard, as an innovative geo-visualization tool, is widely used for interactively visualizing and mining georeferenced information (Jing, Du, Li \& Liu, 2019). For example, the Dublin Dashboard (McArdle \& Kitchin, 2016) embeds maps in different modules which allow users to monitor the city of Dublin from environmental and transport perspectives. The map element in the City of Sydney Dashboard (Pettit, Lieske \& Jamal, 2017) focuses on providing real-time monitoring of different types of transportation. The Galway dashboard ('Visualising the Social and Cultural Infrastructure in Galway City and County', 2015) combines maps with interactive charts to describe the commuting, housing and cultural infrastructures in Galway City and County, Ireland.

While a dashboard, as a visualization method, answers the 'what?' questions, visual analytics exploits dynamic, iterative processes to help people answer 'why?' questions. It combines the computational power of modern computers with human background knowledge and perceptions to solve complex problems (Andrienko et al., 2010; Keim, Mansmann \& Thomas, 2010). Visual analytics methods are utilized by decision makers to drive the optimization of city services, mobility, sustainability, economy and citizen engagement (De Amicis et al., 2009; Karduni et al., 2017; Li, Bao, Sellis, Yan \& Zhang, 2018; Senaratne et al., 2018). To answer the 'what' and 'why' questions within one application, several studies integrated visual analytics approaches with dashboards to explore individual aspects of a city. Würstle, Santhanavanich, Padsala, and Coors (2020) presented a concept for an urban energy dashboard integrated with $3 \mathrm{D}$ city models to compare the computed (projected) energy demand with the actual measured demand in different usage scenarios. Zuo, Ding, and Meng (2020) proposed an analytical dashboard to present and explore the spatio-temporal patterns of multidimensional economic factors in synchronized maps and bar charts.

In this paper, we also propose a web application, a map-based strategical dashboard, to explore the settlement development in Salzburg state and its municipalities. Through a visual analytics approach, the user is able to simulate future settlement development based on existing housing patterns and various land-use scenarios that the user creates. The application provides a platform for decision-making authorities and urban planners to interact with the datasets of existing residential buildings, the stocks of land zoned for residential buildings, and future demands based on population forecasts. It aims to help planning authorities understand the housing potential and the development of the housing demand at both state and municipal scales; it assists them in formulating targeted spatial development concepts for individual municipalities, and thus supports the strategic planning of settlement development. 


\section{Design goals}

In the Alpine Building Centre, RSA FG Research Studio iSPACE develops indicators and interactive web tools to optimize the decision-making process for sustainable spatial development. The application described in this paper is an innovative visualization tool focused on residential land use and settlement development.

The tool is designed for decision-making authorities (here, municipalities in Salzburg state) and their urban planners. According to the guidelines for the spatial development concept (Land Salzburg, 2019), it is vital for them to present the inventory and structure of existing settlements, to analyse earlier developments, and to derive spatial development goals and measures based on the estimated demand for residential building land. Additionally, for an appropriate response to city development and urban planning, analysis of the past, present and future situations is indispensable (Phdungsilp, 2011). The goals of the application therefore focus not only on the simulation of the future settlement development but also on the current residential building structure.

We aim to help users answer the following questions:

- What does the current residential building structure look like in Salzburg state and its municipalities?

- What is the spatio-temporal trend of the development of the reserves of land zoned for residential building in Salzburg state and its municipalities?

- Within land zoned for residential building, is the housing potential sufficient for different building categories? If not, when will the municipalities run out of residential building land?

- If the housing potential is not sufficient to fulfil the forecast demand, what adjustments could be made (e.g. use residential building plots more efficiently by building blocks of flats rather than detached houses) to improve the supply-anddemand situation for housing while avoiding designating more land for residential purposes?

\section{Test Data}

The source data are stored in a file geodatabase. They were processed and structured into a multidimensional data repository as part of the Alpine Building Centre project:

- Future housing demand (2018-2043)

- Existing residential buildings (2018)

- Vacant residential building plots (2018)

The data were converted, using the number of households as a unit, to support the calculation of housing demands, potential and supplies in the pre-set scenario, and in user-defined scenarios, for housing demand and land use (Figure 1). 


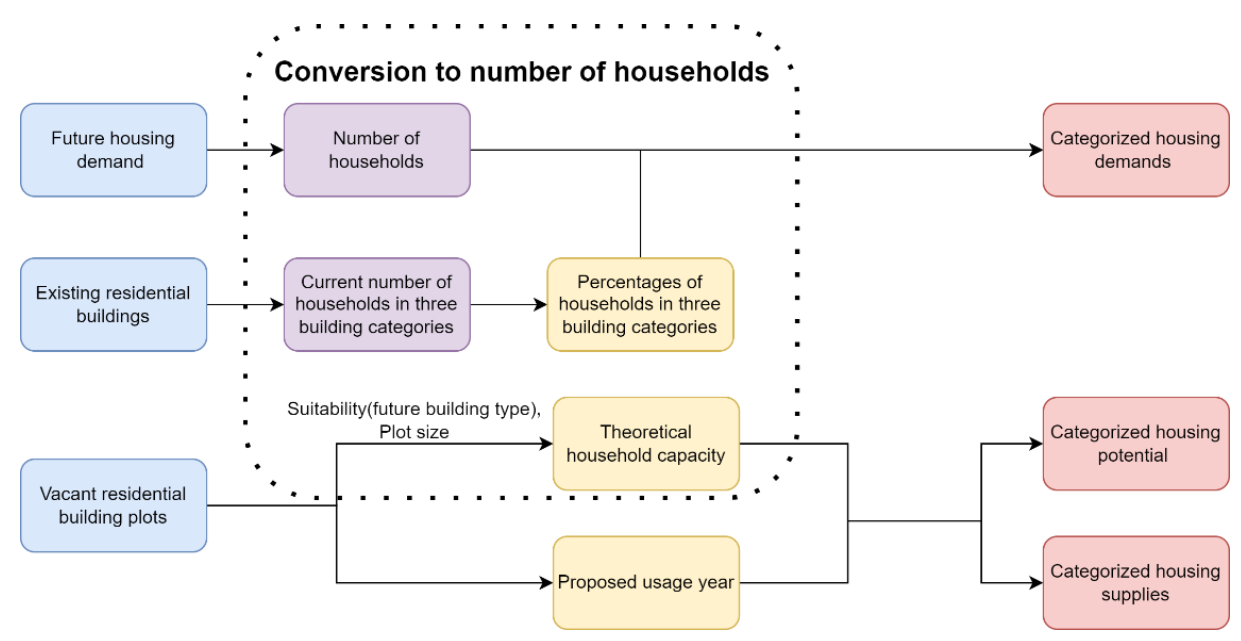

Figure 1: Data usage in the application

In the test dataset, the future housing demand in each municipality is assumed to be equal to the annual changes in the number of households. To calculate the change in the number of households, two factors need to be taken into consideration: (1) population size, and (2) household size (i.e. how many people live in a household). The annual change in the number of households caused by population development is estimated at municipality level, based on the total population number from the statistical data in 2018 and using annual populationchange factors. These factors are calculated from the population forecasts that are available only at district (i.e. supra-municipal) level. As it is common for the population development to vary significantly between municipalities within the same district, the factors are calibrated according to the variability of the population development, from 2002 to 2020, within each district (Figure 2a). The annual changes of household numbers resulting from changes in household size are extrapolated from the number of households at municipality level given in the 2018 data (see Figure 2b). The future yearly housing demand used in this application is the sum of the changes in numbers of households caused by population development + the changes in number of households caused by household size development.

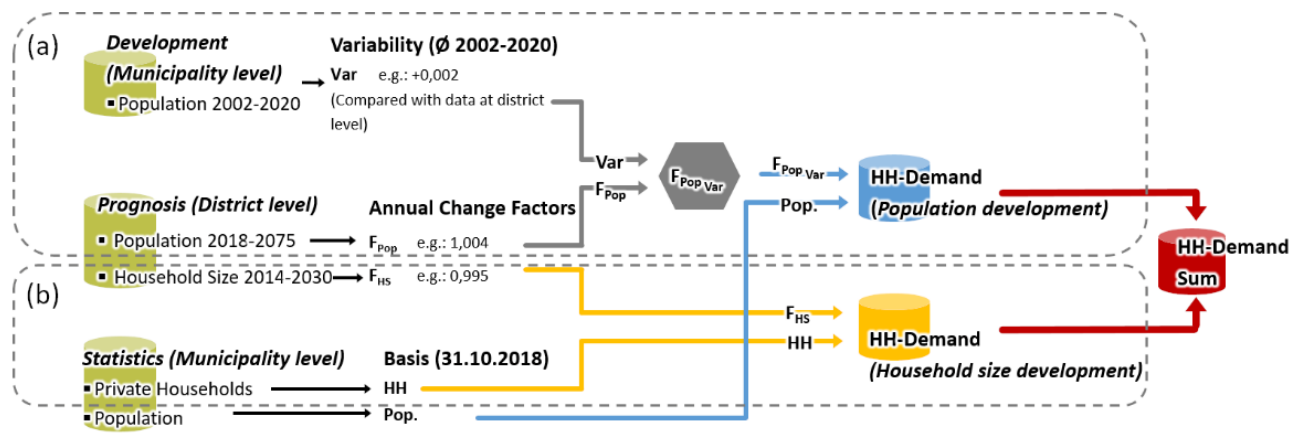

Figure 2: Future housing demand calculation: (a) the calculation of housing demand resulting from changes in size of population; (b) the calculation of housing demand resulting from changes in household size. 
The existing residential buildings are classified into three categories (i.e. housing types): detached houses (Freistehendes Haus), compact low-rise buildings (Verdichteter Flachbau), and blocks of flats (Geschoßwohnbau) (Figure 3). Therefore, in this application, housing demands, potential and supplies are also assigned to these categories. The current household numbers in the building categories are calculated, and their percentages are used to estimate the future demands for different types of housing in the pre-set view. The overarching aim is to represent the projected development of settlement within the context of the overall townscape of municipalities in Salzburg state.

For the vacant zoned residential building land, each building plot is assigned a theoretical household capacity, based on its suitability (optimal future building type) and size. Vacant building plots are aggregated by their suitability and proposed usage year (given in the dataset) to calculate the yearly housing potential and supply for each building category.
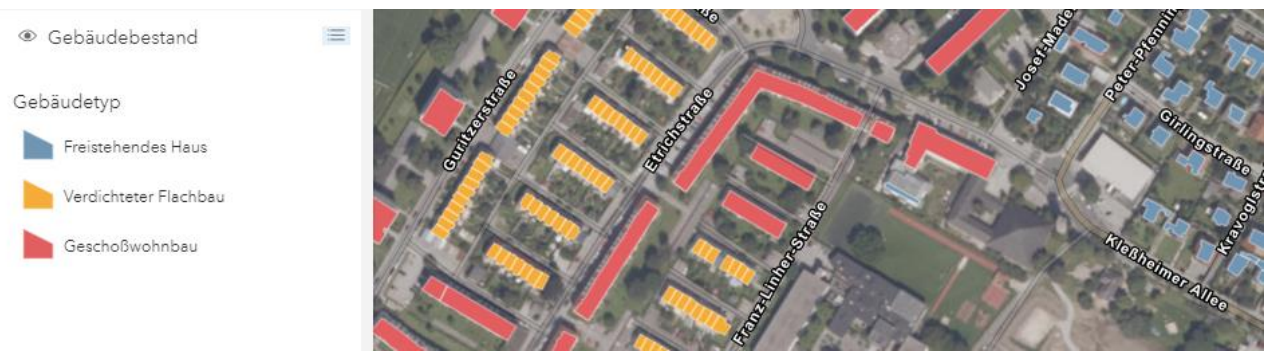

Figure 3: Existing residential buildings classified into three categories: detached houses (blue), compact low-rise buildings (orange), and blocks of flats (red) (Salzburg Maxglan)

\section{Application Architecture}

There are four key elements for the development of the application: feature layers, map, widgets and dashboard. To fulfil the design goals mentioned in Section 2, the application was developed using JavaScript, HTML and CSS, and designed with Calcite Maps, in combination with ArcGIS API for JavaScript, ChartJS and JQuery (Figure 4).

The visualized data are stored as server-side data sources in ArcGIS online, a cloud-based, collaborative content-management system for maps, apps, data and other geographic content (ESRI, 2018). The data are integrated as feature layers in the map. These layers are referenced with unique portal item IDs, and loaded from a REST API service hosted on ArcGIS Online.

We used ArcGIS API for JavaScript (ESRI, 2019) to embed the map and tasks in the web application. Users can interact with the visualized data via the widgets offered in the application to perform several tasks. For example, a municipality selector is integrated to apply a spatial filter to all visualized data; a time slider is embedded to apply a time filter to the land reserve data; an editor widget is used to alter attributes of the vacant building plots. The time slider and the building plot editor were developed from the ready-to-use widgets provided by the ArcGIS API for JavaScript. The municipality selector applies filters to the visualized data by executing query tasks with a 'where' clause applied to the feature layers. In order to visualize 
the results of these operations instantly, we linked these three widgets with the map and the dashboard.

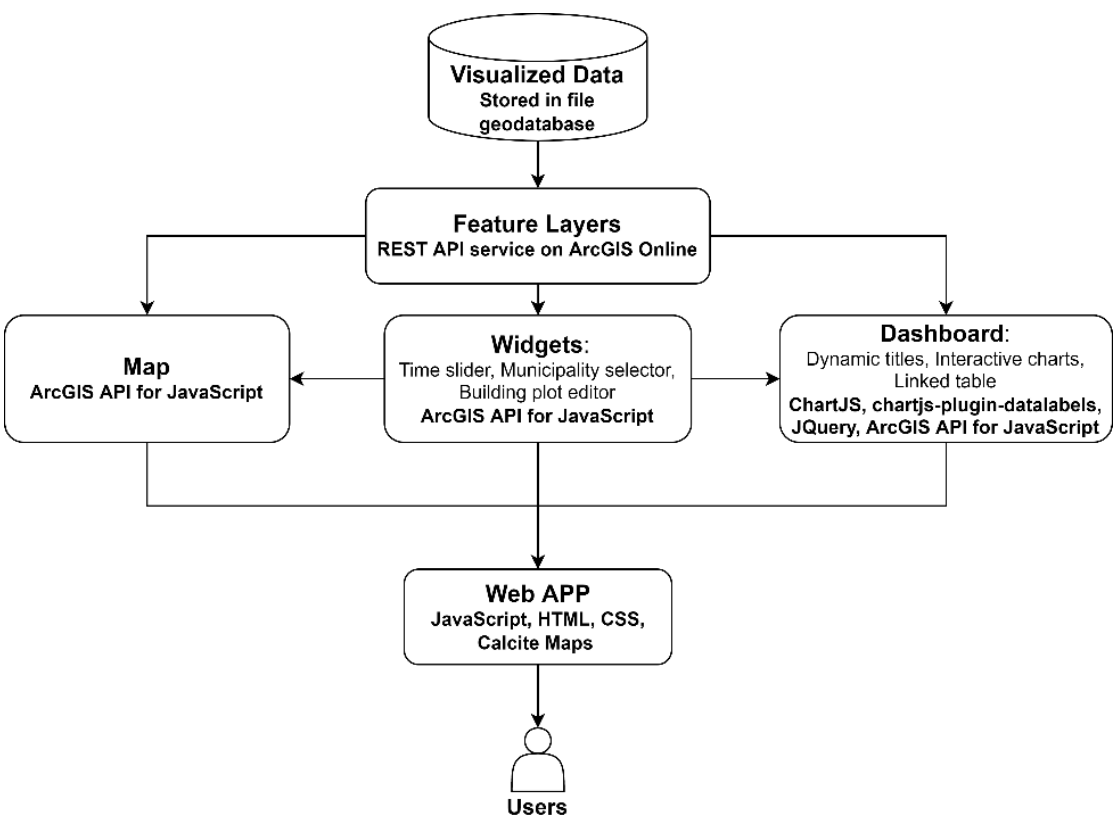

Figure 4: The architecture and libraries used to develop the application features.

Dashboard contents include dynamic titles, interactive charts and a linked table. Their input data are the results of queries on the feature layers. Three types of queries are supported by ArcGIS API for JavaScript: attribute, spatial and statistic queries (ESRI, 2016b). We used attribute queries to fetch attributes (e.g., future demands), and statistic queries to return statistics for fields (e.g., housing potential/supplies by summing up the household capacity of vacant building plots). We used ChartJS (ChartJS, 2016) and chartjs-plugin-datalables (ChartJS, 2017) to create interactive charts in the dashboard. In addition to tooltips on data points and dataset filters, ChartJS also allows updates on the charts when the visualized dataset is modified. With this capability and JQuery (JQuery, 2008), the dashboard is able to provide instant visual feedback on the user's interactions with the application.

The application is built with JavaScript, HTML and CSS, and users have access to it via web browsers. Calcite map is a theme for Bootstrap (Bootstrap, n.d.) for designing, styling and creating modern map apps (ESRI, 2016a). We used it to design the layout of the application, and the layout adapts to the size of the device screen.

\section{$5 \quad$ Results}

This section introduces the application's user interface and a use case in Oberndorf bei Salzburg. The use case demonstrates how the questions which we mentioned in the design goals (Section 2) can be answered through user interactions with the application. 


\subsection{User Interface}

The application follows the 'Visual Information Seeking Mantra - Overview first, zoom and filter, then details-on-demand' (Shneiderman, 1996). Users are able to access information at state, municipality, individual building and building plot levels. Figures $5 \mathrm{a}$ and $5 \mathrm{~b}$ provide overviews of the application's prototypical user interface and its components at two map scales. The user interface has the following components: header, dropdown menu, basic interactive map elements, and task-oriented features.

The header (Figure 5a - A) shows the title of the application, followed by a slogan which briefly explains the application's purpose. The dropdown menu (Figure 5b - B) contains an 'about us' page, basemap gallery, map print service, and toggle to hide the header. Basic interactive map elements include a main map view (Figure 5a - C1), map controls (Figure 5a - C2), layer list (Figure 5a - C3), search window (Figure 5a-C4), and pop-up window (Figure 5b - C5). The map view is the background of the user interface. Map controls include zoom control, home button for resetting the map extent, and full-screen control. The layer list indicates the map layers that are visible, and adapts automatically according to the map scale selected by the user. It has an integrated foldable map legend. Users can also display or hide layers manually with the 'eye-shaped' toggle (as seen in Figure 3). When a larger scale is applied to the map, users are can view attributes of the building or building plot selected, which appear in a pop-up window. Task-oriented features include a time slider (Figure 5a - D1), dashboard (Figure 5a D2), building plot editor (Figure 5a - D3), and municipality selector (Figure 5a - D4). To ensure the user interface is not overcrowded, the latter three features are wrapped in collapsible elements. The application therefore stays uncluttered and clear for users, who need to view only the current and projected settlement development.

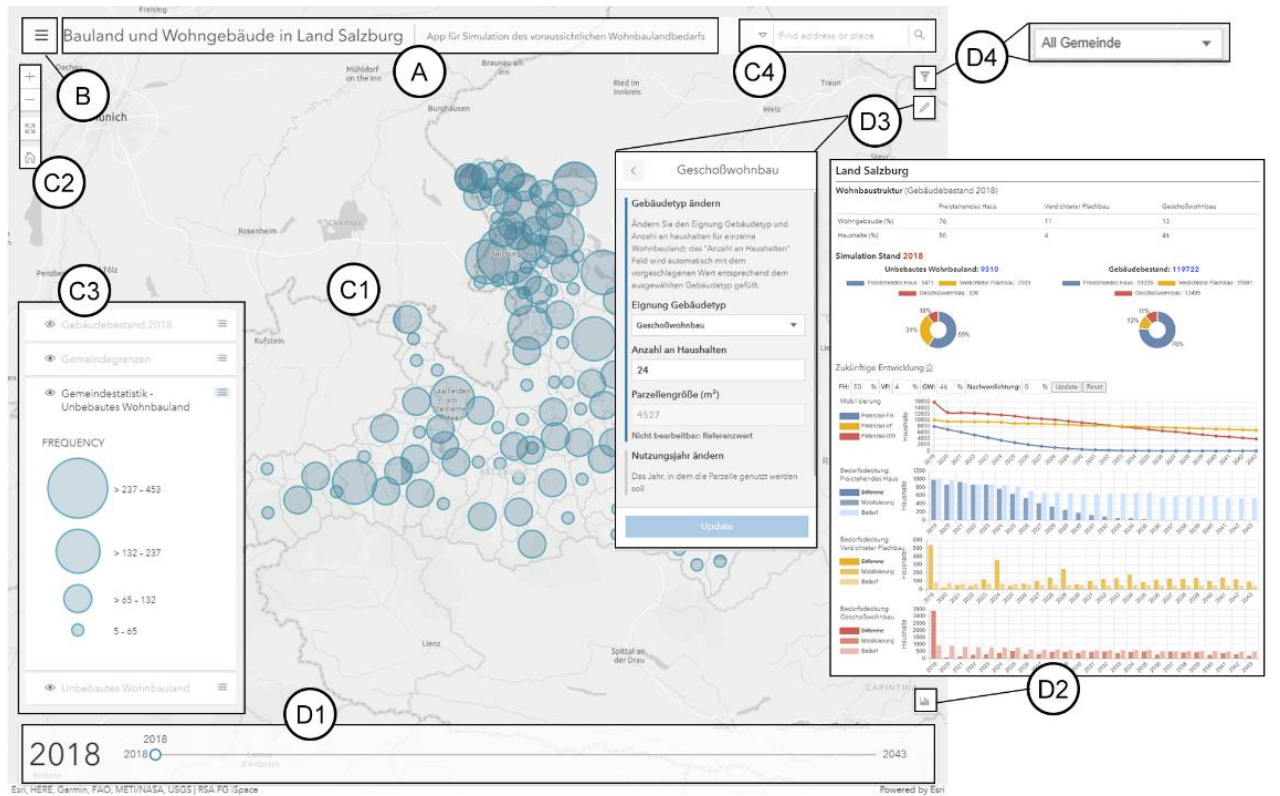

(a) 


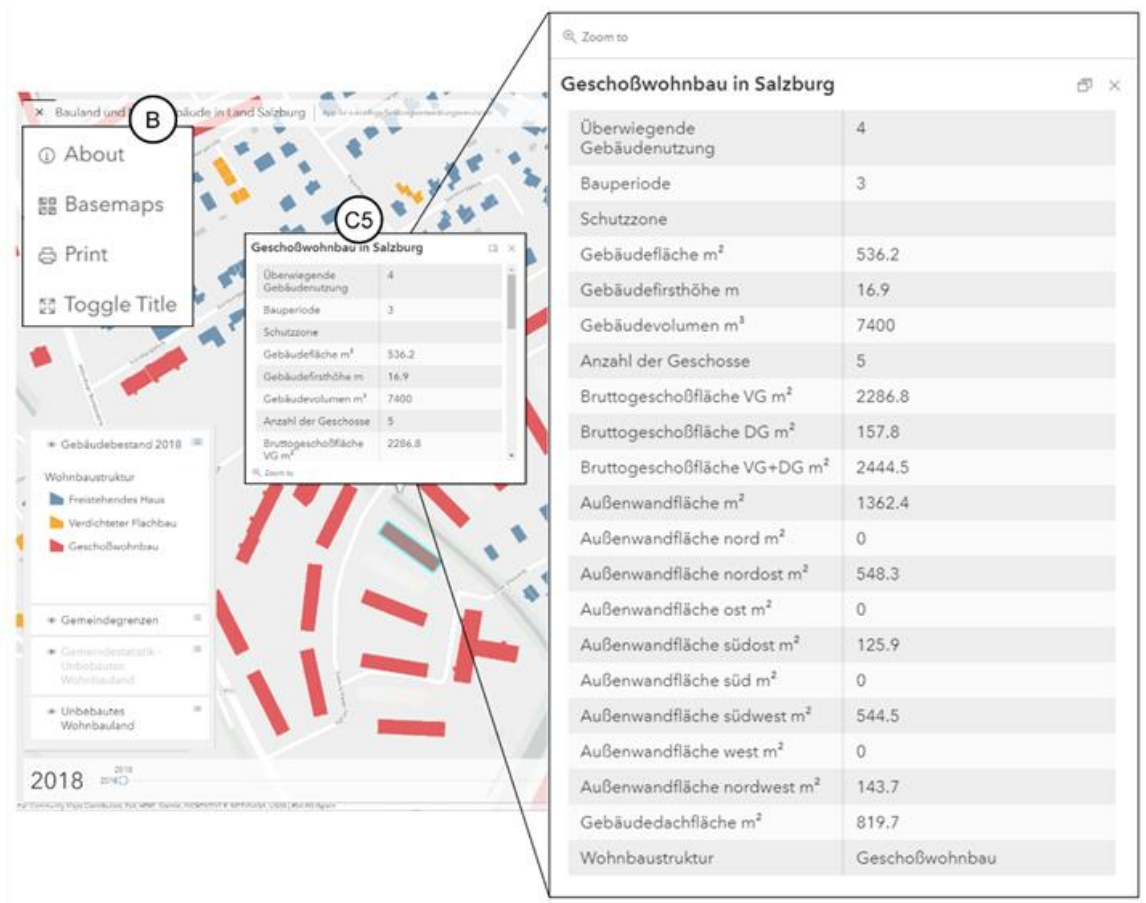

(b)

Figure 5: User Interface. (a) At state scale: header (A), dropdown menu (B), basic interactive map elements (C1-C4), and task-oriented features (D1-D4). (b) At building scale, the map shows three types of existing residential building; expanded dropdown menu (B), pop-up window of a selected block of flats (C5).

\subsection{Use Case - Oberndorf bei Salzburg}

Oberndorf bei Salzburg is a municipality in the north of Salzburg state. The use case allows us to answer the questions listed in the design goals (see Section 2).

After selecting Oberndorf using the municipality selector, the municipality border of Oberndorf and the spatial distribution of its vacant reserves of zoned residential building land in 2018 are shown on the map (Figure 6a). The spatial extent of the dataset visualized is limited to Oberndorf. This allows users to explore the settlement development of individual municipalities separately. As the housing supply and demand situations in each municipality differ greatly from each other, an overview of the settlement situation at the level of the state is inadequate. To support optimal decision-making, it is essential to provide users with views at both state and municipality level.

The table in the dashboard shows the proportions of buildings and numbers of households in the three building categories (Figure 6b). It allows users to see at a glance the current residential building structure in Oberndorf. We can see that the majority of the present residential buildings there are detached houses. These account for $69 \%$ of all residential buildings. Nevertheless, almost the same number of households reside in detached houses as in blocks of flats, which account for just $10 \%$ of the buildings. 
Using the time slider, we can see how the zoned residential land reserve may evolve numerically and spatially over the next 25 years. The dynamic pie charts and their legends help users monitor the consumption of each type of land reserve and how this affects the building stock (Figure 6c). From the pie chart on the left, we can see that at the beginning of 2018, most vacant, zoned, residential building land was suitable for detached houses, while plots suited for compact low-rise buildings came second. In the map view, land reserves that are likely to be used in the near future are greyed out as users interact with the time slider. Figures $6 \mathrm{~d}$ and $6 \mathrm{e}$ show the spatial distribution of the vacant residential building plots in northern Oberndorf in 2018 and 2030. This provides users with a clear image of how the land reserved for residential building evolves spatially over time.

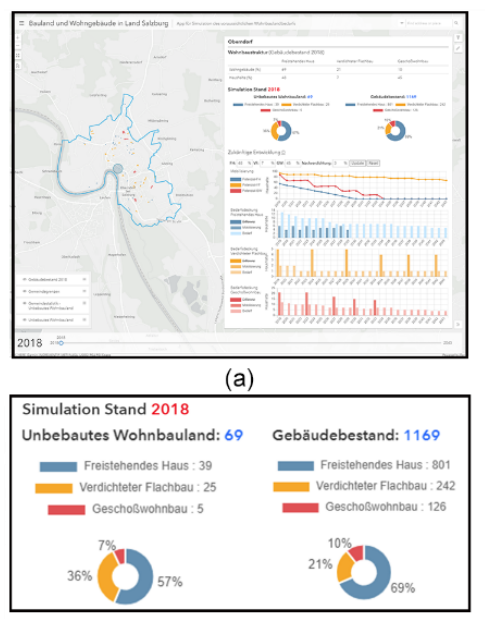

(c)

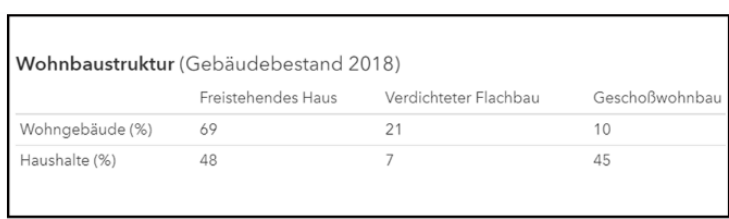

(b)

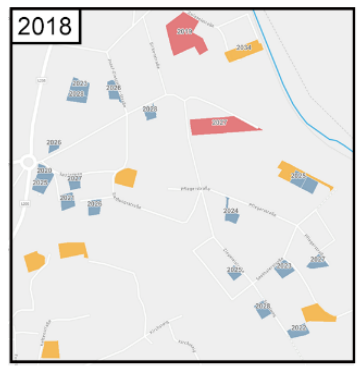

(d)

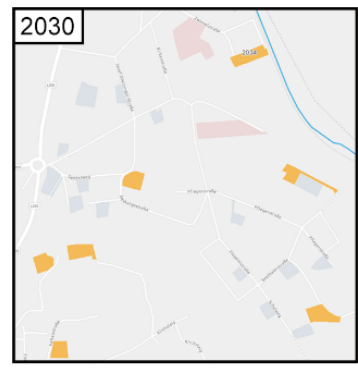

(e)

Figure 6: Use case in Oberndorf bei Salzburg. (a) Application with the expanded dashboard. It describes the residential buildings and building land reserve for settlement in 2018. (b) Table in the dashboard for types of housing. (c) Pie charts in the dashboard for vacant residential building land (left) and existing residential buildings (right) in 2018. (d) Vacant residential building land in 2018. (e) Vacant residential building land in 2030.

The serial charts in the dashboard (Figure 6a) show the projected yearly housing potential, demand and supply in terms of number of households. These help users to evaluate the projected future settlement situation. The pie chart in the dashboard (Figure 6c, left) shows that most vacant building plots are suitable for detached houses. However, based on the demands and proposed usage forecast for each year and for each vacant building plot, the potential for building detached houses is insufficient and will be the first to run out (in 2030) (Figure 7 - A). Compared to the demands forecast, building land in this category is insufficient (Figure 7 - B1). The graph in Figure 7 - B2 shows the cumulative difference between the projected housing demands and supplies. We can see that in the default scenario, due to the continuous gap between demand and supply, the total difference keeps increasing. For example, by 2030 there is a total housing shortfall of 57 housing units, yet most land reserve suited for compact low-rise buildings is unused. At the beginning of 2030, there is still the potential to build compact low-rise buildings that would provide 79 households with housing (Figure 7 - A). 
As the serial charts depict, the housing potential is apparently insufficient for some building categories (as just described for detached houses). The web map therefore offers the possibility of creating user-defined scenarios: in the input fields, users can adapt the proportions of the demand, for example lowering the demand for detached houses while increasing that for compact low-rise buildings (Figure 7 - C). Users can also increase the re-densification index (Figure 7 - D) to reduce the demand for building land and fulfil more of the housing demand by densifying the existing building stock. Furthermore, users can adjust the use of individual building plots (e.g., change future building type, increase theoretical household capacity, adjust usage year) via the building plot editor (Figure 8). With one building type selected, a new theoretical household capacity is calculated automatically based on the building type and building plot size. Housing potential, supply and demand are immediately recalculated based on the modified parameters and visualized by the charts in the dashboard. Using also their human perception, decision makers can evaluate their alternative scenarios for housing demand and residential land use intuitively. These simulations can help users to test measures that could improve the imbalance between the supply and demand of housing, while avoiding re-designating for residential buildings land that has already been zoned for other purposes (e.g. as green spaces). Ultimately, the application can help municipalities and planners to identify the potential shortfall of housing at a fine-gained scale, and to formulate the optimal land-use concept customized for their own area.

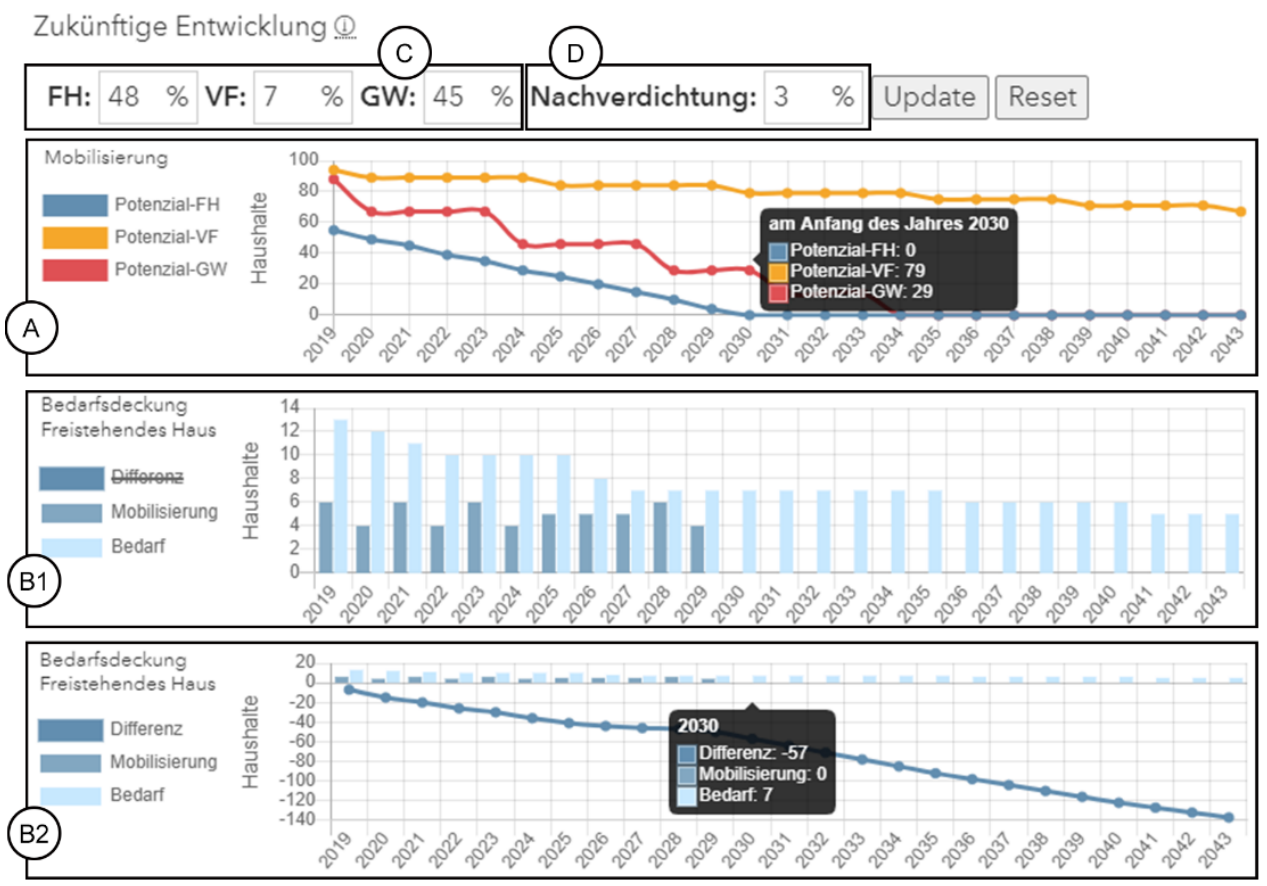

Figure 7: Use case in Oberndorf bei Salzburg. Serial charts: (A) yearly housing potential of three building categories; (B1) yearly housing supply and demand for detached houses, without cumulative difference line; (B2) yearly housing supply and demand for detached houses with cumulative difference line. All values are calculated as number of households. Input fields (top): (C) proportions of demands for each building category; (D) re-densification index. 


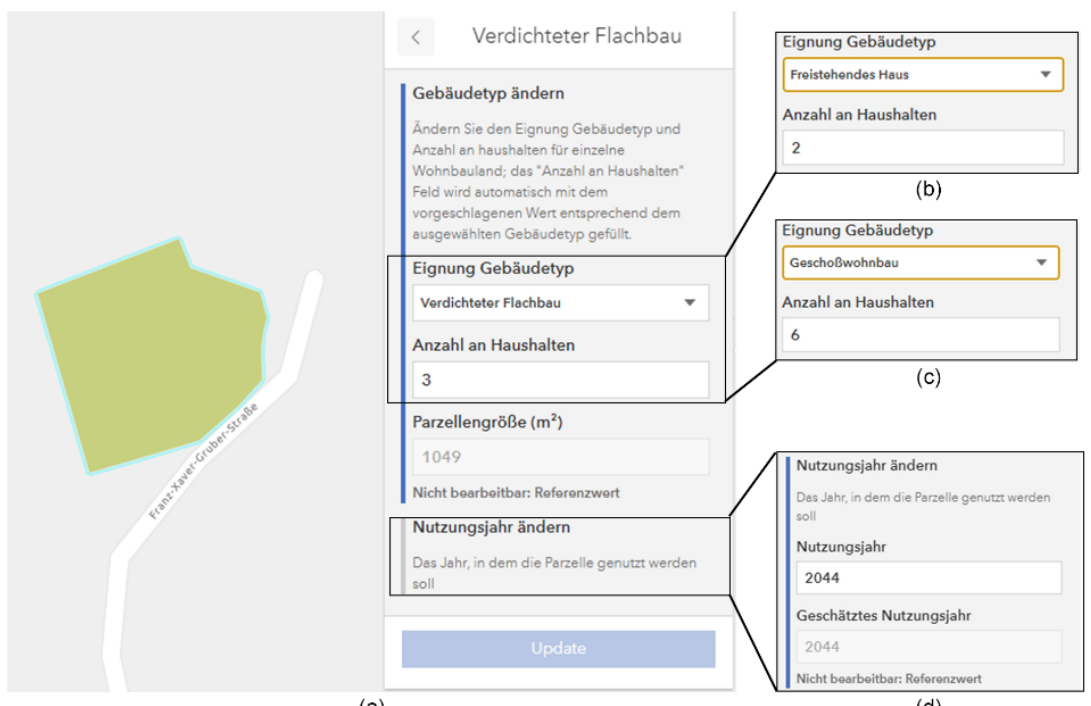

(a)

(d)

Figure 8: Using building plot editor: (a) expanded panel for editing building type and household capacity; (b) building type 'Detached house' selected; (c) building type 'Block of flats' selected; (d) expanded panel for editing usage year.

\section{Conclusion and Outlook}

In this paper, we introduced the prototype of a web application developed within the framework of the Alpine Building Centre (Zentrum Alpines Bauen). The application is a mapbased strategical dashboard for the exploration of the settlement development in Salzburg state and its municipalities. The paper describes the design goals, data preparation, architecture and user interface of the application. With the use case in Oberndorf bei Salzburg, we demonstrated how the prototype fulfils its design goals: for Salzburg state and its municipalities, it visualizes the current spatial distribution and structure of residential buildings and zoned residential building land reserve using maps, tables and pie charts in the dashboard. With the time slider, the application is able to describe the forecast settlement and changes in the land reserve dynamically. By quantifying the land reserve with reference to household capacity and linking it with future demands that are calculated using forecasts for population and household sizes, users can explore, with the help of serial charts, whether land reserves are sufficient. Furthermore, using a visual analytic approach, users are able to simulate and evaluate various hypothetical scenarios for housing demand and residential land use. The application helps decision makers to follow the guidelines for the spatial development concept (Land Salzburg, 2019) for municipalities in Salzburg state, by offering them a platform to reflect on existing housing patterns and to experiment with alternative land-use scenarios. Information derived from this application can be used as a basis to formulate spatial development concepts for individual municipalities in Salzburg state, with the aim of improving future housing supply in the current reserves of land zoned for residential buildings, according to the various municipalities' individual trends in the development of population and household size. This paper presents the application as an approach that uses an interactive 
map-based dashboard to present and utilize multi-dimensional data in the field of residential land use in urban planning. The application can be easily adapted for other municipalities or states.

The development of the web application is still in progress. We have presented it to a number of municipalities and urban planners in Salzburg state for initial feedback. Feedback for the concepts used has been positive, and planners and municipalities have shown interest in the prototype. Other feedback includes a suggestion to integrate the application with spatial data for re-densification potential, adding indicators that represent the actual availability of vacant zoned lands, and increasing the time interval used on the time slider and the serial charts. The current one-year interval is too short and thus not suitable for residential land-use planning. In future work within the Alpine Building Centre project, we will modify the application to take these suggestions into account. In addition, an evaluative study of the interactive mapbased design of the dashboard is necessary to justify the design. With a view to improving the application, we therefore plan to conduct a usability study to evaluate the application with urban planners and decision-making authorities from pilot municipalities.

\section{Acknowledgements}

The web application for simulating the development of future settlement was developed by Research Studio iSPACE at the Alpine Building Centre (Zentrum Alpines Bauen) in the key research area 'simulation of settlement systems'. The Alpine Building Centre is a cooperation between the RSA FG Research Studio iSPACE and Salzburg University of Applied Sciences. It is funded by Salzburg state and IWB EFRE.

Thomas Prinz (co-author) would like to thank University of Salzburg (PLUS) - IDA Lab (20204-WISS/225/197-2019 and 0102-F1901166-KZP) for their support.

\section{References}

Andrienko, G., Andrienko, N., Demsar, U., Dransch, D., Dykes, J., Fabrikant, S. I., . . Tominski, C. (2010). Space, time and visual analytics. International Journal of Geographical Information Science, 24(10), 1577-1600. doi:10.1080/13658816.2010.508043

Bayerisches Landesamt für Umwelt. (2018). Flächenmanagement-Datenbank: praktische Hilfe für Kommunen. Retrieved from https://www.lfu.bayern.de/umweltkommunal/flaechenmanagement/fmdb/index.htm

Bootstrap. (n.d.). Build fast, responsive sites with Bootstrap. Retrieved from https://getbootstrap.com/

ChartJS. (2016). Chart.js: Open source HTML 5 Charts for your website. Retrieved from https://www.chartjs.org

ChartJS. (2017). chartjs-plugin-datalabels: Display labels on data for any type of charts. Retrieved from https://chartjs-plugin-datalabels.netlify.app

De Amicis, R., Conti, G., Simões, B., Lattuca, R., Tosi, N., Piffer, S., \& Pellitteri, G. (2009). Geovisual analytics for urban design in the context of future internet. International Journal on Interactive Design and Manufacturing (IJIDeM), 3(2), 55-63. doi:10.1007/s12008-009-0060-1 ESRI. (2016a). Calcite Maps. Retrieved from https://esri.github.io/calcite-maps/samples/index.html 
ESRI. (2016b). Query. Retrieved from https://developers.arcgis.com/javascript/latest/apireference/esri-tasks-support-Query.html\#

ESRI. (2018). Working with the ArcGIS Platform. Retrieved from https://developers.arcgis.com/javascript/latest/guide/working-with-platform/

ESRI. (2019). ArcGIS API for JavaScript. Retrieved from https://developers.arcgis.com/javascript/

Jing, C., Du, M., Li, S., \& Liu, S. (2019). Geospatial Dashboards for Monitoring Smart City Performance. Sustainability, 11(20), 5648. doi:10.3390/su11205648

JQuery. (2008). JQuery: The Write Less, Do More, JavaScript Library. Retrieved from https://jquery.com/

Karduni, A., Cho, I., Wessel, G., Ribarsky, W., Sauda, E., \& Dou, W. (2017). Urban Space Explorer: A Visual Analytics System for Urban Planning. IEEE Computer Graphics and Applications, 37(5), 50-60. doi:10.1109/mcg.2017.3621223

Keim, D. A., Mansmann, F., \& Thomas, J. (2010). Visual analytics: how much visualization and how much analytics? ACM SIGKDD Explorations Newsletter, 11(2), 5-8.

Land Salzburg. (2019). Leitfaden: Räumliches Entwicklungskonzept. Retrieved from https://www.salzburg.gv.at/bauenwohnen_/Documents/2019_11_06_REK-Leitfaden.pdf

Li, M., Bao, Z., Sellis, T., Yan, S., \& Zhang, R. (2018). HomeSeeker: A visual analytics system of real estate data. Journal of Visual Languages \& Computing, 45, 1-16.

McArdle, G., \& Kitchin, R. (2016). The Dublin Dashboard: Design and development of a real-time analytical urban dashboard., III-4/W1, 19-25. doi:10.5194/isprs-annals-iii-4-w1-19-2016

Pettit, C., Lieske, S. N., \& Jamal, M. (2017). CityDash: Visualising a Changing City Using Open Data. In (pp. 337-353): Springer International Publishing.

Phdungsilp, A. (2011). Futures studies' backcasting method used for strategic sustainable city planning. Futures, 43(7), 707-714.

Rheinland-Pfalz. (2015). RAUM+Monitor. Retrieved from https://mdi.rlp.de/de/unserethemen/landesplanung/raum-monitor/

Senaratne, H., Mueller, M., Behrisch, M., Lalanne, F., Bustos-Jimenez, J., Schneidewind, J., . . . Schreck, T. (2018). Urban Mobility Analysis With Mobile Network Data: A Visual Analytics Approach. IEEE Transactions on Intelligent Transportation Systems, 19(5), 1537-1546. doi:10.1109/tits.2017.2727281

Shneiderman, B. (1996, 3-6 Sept. 1996). The eyes have it: a task by data type taxonomy for information visualizations. Paper presented at the Proceedings 1996 IEEE Symposium on Visual Languages.

Visualising the Social and Cultural Infrastructure in Galway City and County. (2015). Retrieved from http://galwaydashboard.ie/social

Würstle, P., Santhanavanich, T., Padsala, R., \& Coors, V. (2020). The Conception of an Urban Energy Dashboard using 3D City Models. Paper presented at the Proceedings of the Eleventh ACM International Conference on Future Energy Systems.

Zuo, C., Ding, L., \& Meng, L. (2020). A Feasibility Study of Map-Based Dashboard for Spatiotemporal Knowledge Acquisition and Analysis. ISPRS International Journal of GeoInformation, 9(11), 636. doi:10.3390/ijgi9110636 